\title{
KESANTUNAN BERBAHASA DEWAN JURI RAGAM ACARA "BERAKSI DI RUMAH SAJA" DI INDOSIAR (KAJIAN SOSIOPRAGMATIK)
}

\author{
Muhammad Hasbullah Ridwan ${ }^{1}$, Nurul Khamidah ${ }^{2}$ \\ e-mail: hasbullahridwan@iaida.ac.id ${ }^{1}$, khamidahnurul61@ gmail.com ${ }^{2}$ \\ Prodi Tadris Bahasa Indonesia \\ IAI Darussalam Blokagung Banyuwangi
}

\begin{abstract}
Abstrak
Berbahasa dengan cara yang baik dan santun merupakan aturan dalam berkomunikasi agar komunikasi dapat berjalan dengan lancar dan maksud perbincangan atau tujuan dari komunikasi dapat tercapai. Komunikasi antar individu atau kelompok dapat terjadi di berbagai tempat baik itu dalam lingkungan keluarga, tempat kerja dan lainnya. Selain itu, komunikasi dapat ditemukan pada koran, tabloid, majalah salah dan siaran televisi. Salah atu acara televisi yang memperlihatkan adanya komunikasi antar seseorang adalah dalam ragam acara "BerAKSI di Rumah Saja" di Indosiar. Sejalan dengan hal di atas, tujuan penelitian ini adalah untuk menganalisis pemenuhan prinsip kesantunan berbahasa, pelanggaran prinsip kesantunan berbahasa dan melihat faktor apa saja yang mempengaruhi pelanggaran prinsip kesantunan berbahasa dewan juri ragam acara "BerAKSI di Rumah Saja" di Indosiar. Penelitian ini menggunakan metode penelitian deskriptif kualitatif yang menguraikan dan menyajikan data-data yang diperoleh secara faktual dan akurat. Data untuk penelitian ini adalah tuturan dewan juri ragam acara "BerAKSI di Rumah Saja" di Indosiar yang diduga memenuhi prinsip kesantunan berbahasa dan melanggar prinsip kesantunan berbahasa. Teknik pengumpulan data yang dilakukan dalam penelitian ini adalah teknik simak, teknik catat, dan reduksi data. Hasil penelitian menunjukan adanya pemenuhan terhadap prinsip kesantunan berbahasa dalam (1) maksim kebijaksanaan, (2) maksim kemurahan, , (3) maksim kerendahan hati, (4) maksim kecocokan, (5) maksim kesimpatian. Selanjutnya hasil penelitian mengenai tuturan yang melanggar terhadap prinsip kesantunan berbahasa yang diklasifikaiskan pada faktor-faktor penyebab pelanggaran prinsip kesantunana berbahasa (1) sebab kritikan secara langsung dengan kata-kata kasar, (2) faktor dorongan rasa emosi penutur, (3) faktor sengaja menuduh lawan tutur, (5) faktor sengaja memojokkan lawan tutur sebanyak.

Kata kunci: kesantunan berbahasa, dewan juri
\end{abstract}

\begin{abstract}
Speaking in a good and polite way is a rule in communicating so that communication can run smoothly and the purpose of discussion or the purpose of communication can be achieved. Communication between individuals or groups can occur in various places be it in the family environment, workplace and others. In addition, communications can be found on newspapers, tabloids, wrong magazines and television broadcasts. One of the television shows that shows the existence of communication between people is in various events "BerAKSI at Home Only" in Indosiar. In line with the above, the purpose of this study is to analyze the fulfillment of the principle of language impression, violation of the principle of language impression and see what factors influence the violation of the principle of language impression of
\end{abstract}


the jury variety of events "BerAKSI at Home Only" in Indosiar. This research uses descriptive qualitative research method that describes and presents the data obtained factually and accurately. The data for this study is the speech of the jury of various events "BerAKSI at Home Only" in Indosiar that allegedly fulfilled the principle of language impressionion and violated the principle of language impression. Data collection techniques carried out in this research are listening techniques, noterecording techniques, and data reduction. The results showed the fulfillment of the principle of language impression in (1) the maksim of wisdom, (2) the max of generosity, , (3) the maksim of humility, (4) the maksim of the match, (5) the maksim of pympaness. Furthermore, the results of research on speech that violates the principle of language impressions that are diklasifikaiskan on the factors that cause violations of the principle of language impression (1) because of criticism directly with harsh words, (2) factors of encouragement of the sense of emotion of speakers, (3) factors deliberately accusing the opponent of speech, (5) factors deliberately cornering the opponent as much.

Keywords: language impressions, jury

\section{A. Pendahuluan}

Setiap hari manusia tidak lepas dari kegiatan berkomunikasi atau berinteraksi antar sesamanya. Salah satu yang berperan penting dalam kegiatan berkomunikasi adalah bahasa. Wardaugh dalam (Chaer, 2018: 33) yang mengatakan fungsi bahasa adalah alat berkomunikasi bagi manusia. Suharmono (dalam jurnal Ellysya Sulistyo S, 2017) mengungkapkan bahwa dalam kegiatan berbahasa yang perlu dimiliki oleh semua orang, yaitu menyimak, berbicara, dan berpendapat. Keterampilan berbicara seseorang dalam berbahasa sangat memengaruhi dalam interaksi sosialnya di masyarakat. Seseorang yang terampil dalam menempatkan posisi atau terampil dalam menggunakan keterampilan berbicaranya dalam berbahasa yang disertai dengan tindak tutur yang sesuai dapat memudahkannya untuk berinteraksi dengan baik. Tidak jarang orang yang belum memahami bagaimana cara bertindak tutur yang sesuai agar dapat berinteraksi dengan baik di lingkungannya. Kesalahan dalam berbicara tidak lain merupakan karena penyimpangan terhadap prinsip-prinsip kesantunan dalam berbahasa. Kaidah kesantunan dipakai dalam setiap tindak bahasa. Supratno (dalam jurnal Ellysya Sulistyo S, 2019) mengungkapkan bangsa Indonesia merupakan bangsa yang multikultural, tetapi bisa hidup berdampingan, saling menghormati, saling menghagai saling toleransi, dan bisa berkomunikasi secara santun. Bahasa memiliki beberapa tataran bahasa yang di dalamnya terdapat sebuah kajian yang membahas prinsip-prinsip kesantunan dalam berbahasa salah satunya yaitu kajian 
sosiopragmatik, sebuah ilmu dalam tataran bahasa Indonesia yang membahas tentang kesantunan berbahasa.

Lingkungan menjadi tempat bagi masyarakat dalam melakukan kegiatan berinteraksi atau berkomunikasi. Lingkungan terbagi menjadi beberapa macam diantaranya lingkungan keluarga, lingkungan sekolah, tempat kerja, dan lain-lainnya. Lingkungan menjadi salah satu faktor penggunaaan bahasa seseorang dalam berinteraksi. Lingkungan juga memengaruhi keberagaman berbahasa seseorang. Hal ini dikarenakan banyaknya keberagaman budaya, tradisi ataupun bahasa yang digunakan di dalam suatu lingkungan. Selain itu, profesi seseorang juga memengaruhi interaksi atau cara bicara seseorang. Latar belakang profesi tersebut biasanya membuat seseorang memiliki ciri khas tersendiri dalam penggunaan bahasa ketika berinteraksi entah itu didasari pada pembawaan tradisi ataupun pendidikan. Latar belakang profesi yang dipengaruhi oleh lingkungan tempat tinggal ataupun tempat bekerja juga membuat seseorang berusaha untuk menempatkan diri sesuai dengan lingkungannya ketika melakukan kegiatan berkomunikasi. Komunikasi antar seseorang dengan yang lainnya dikatakan baik apabila maksud dan tujuan dapat dipahami oleh mitra tutur. Tuturan yang kita ucapkan sejatinya bukanlah sebuah tuturan-tuturan kosong tanpa adanya sebuah kandungan tindakan di dalamnya ataupun kosong dari konteks (Ridwan, 2017:6). Ma'arif (2021:152) menyatakan bahasa dipandang secara umum sebagai sarana komunikasi yang khas dan unik oleh penggunanya.

Wujud penggunaan bahasa dapat dijumpai pada media-media komunikasi, baik media elektronik seperti televisi dan radio serta media cetak seperti koran, tabloid, dan majalah. Salah satu media yang menampilkan penggunaan bahasa yang sering terjadi adalah televisi. Banyak sekali program televisi yang menampilkan percakapan, narasi dan bentuk pengunaaan bahasa lainnya. Saat ini, beberapa stasiun televisi di Indonesia berlomba-lomba membuat program acara di televisi semenarik mungkin. Di antara program televisi yang saat ini menjadi tontonan hiburan bagi masyarakat adalah program ragam acara. Program ragam acara merupakan sebuah program acara televisi yang menunjukkan keragaman hiburan sesuai dengan tema yang diangkat oleh acara tersebut. Keberhasilan penyelenggaraan ragam acara tidak terlepas dari pekerja di dalamnya seperti produser, staf maupun pengisi acara. Jika pamor sebuah acara semakin meningkat akan menimbulkan pro kontra tanggapan 
masyarakat. Hal itu mengindikasikan kalau acara tersebut menarik perhatian para permisa.

Ragam acara "BerAKSI di Rumah Saja" merupakan salah satu program acara di stasiun televisi yaitu Indosiar. Program acara tersebut merupakan sebuah acara ajang pencarian bakat da'i di Indonesia untuk menampilkan bakat mereka dalam berdakwah. Acara yang rutin diselenggarakan oleh Indosiar setiap tahun ini, kini membuat konsep baru dalam menyelenggarakan acara di tengah pandemi wabah Covid -19. Kalau dulu acara ini diselenggarakan dengan penuh kemeriahan dari para peserta lomba dan para pendukung, acara tersebut kini mengikuti aturan protokol kesehatan dengan tidak menghadirkan peserta lomba dan para pendukung dalam satu studio. Ragam acara ini menampilkan bakat dari para peserta lomba melalui layanan daring dan penilaian penampilan peserta ditentukan melalui voting dari para pendukung masing-masing peserta lomba.

Melihat dari besarnya acara tersebut tentu banyak sekali kegiatan komunikasi atau interaksi yang terjadi. Tentunya dalam sebuah komunikasi, bahasa menjadi peran utama di dalamnya. Seperti yang kita bahas sebelumnya, dalam berbahasa kita harus banyak memerhatikan banyak hal. Diantaranya yaitu prinsip kesantunan. Melihat dari banyaknya orang-orang yang terlibat baik itu para karyawan ataupun pembawa acara dan pengisi acara yang lainnya, peneliti hanya memfokuskankan pada percakapan atau tindak tutur dewan juri ragam acara saja. Karena, peneliti melihat dari latar belakang dan profesi ketiga dewan juri yang pertama yaitu ustad Sholeh Mahmud, ustad Subki Al-Bughury, dan ustad Taufiqurrahman yang tidak lain ketiganya adalah seorang pendakwah atau mubalig, tentunya keseharian mereka menggunakan bahasa dalam berkomunikasi tidak lepas dari tata krama atau cara berbicara yang baik. Dari latar belakang para dewan juri pula tentunya bahasa yang digunakan mereka sehariharinya sangat berkaitan dengan tema peneliti kali ini yaitu kesantunan berbahasa. Sehingga hal ini menarik peneliti untuk mengonsentrasikan penelitian pada tindak tutur dewan juri dalam acara tersebut. Dengan adanya penelitian ini penulis berharap tulisan ini dapat dijadikan salah satu media pembelajaran bagi para pembaca dan masyarakat pada umumnya untuk menambah wawasan dan pengetahuan mengenai bahasa. 


\section{Pengertian Bahasa}

Menurut Chaer (2018: 30), bahasa adalah alat verbal untuk komunikasi. Sebelumnya, Chaer menegaskan bahwa bahasa sebagai suatu lambang bunyi yang bersifat arbiter yang digunakan oleh sekelompok anggota masyarakat untuk berinteraksi dan mengidentifikasi diri.

Dalam jurnal (Rina Devianty, 2017: 226) Kemampuan berbahasa merupakan kemampuan yang dimiliki manusia dan membedakan manusia dengan makhluk Tuhan lainnya. Bahasa memungkinkan manusia untuk menyampaikan informasi dan meneruskan informasi tersebut dari satu generasi ke generasi berikutnya melalui ungkapan secara tertulis. Bahasa juga dapat memengaruhi arah perilaku manusia. Kemampuan bahasa, pikiran, perasaan, dan penalaran seseorang dapat dirangsang dan dilatih agar fungsi bahasa dapat dirasakan lebih efektif lagi.

Kedudukan bahasa sebagai bahasa nasional, bahasa Indonesia berfungsi sebagai: (1) lambang kebanggaan kebangsaan; (2) lambang identitas nasional; (3) alat perhubungan antar warga, antar daerah, dan antar budaya; dan (4) alat yang memungkinkan penyatuan berbagai suku bangsa dengan latar belakang sosial budaya dan bahasanya masing-masing ke dalam kesatuan kebangsaan Indonesia. Dalam kedudukannya sebagai bahasa negara, bahasa Indonesia berfungsi sebagai: (1) bahasa resmi kenegaraan; (2) bahasa pengantar di dalam dunia pendidikan; (3) alat perhubungan pada tingkat nasional untuk kepentingan perencanaan dan pelaksanaan pembangunan; dan (4) alat pengembangan kebudayaan, ilmu pengetahuan dan teknologi.

\section{Pengertian Sosiopragmatik}

kata sosio dan pragmatik. Sosio 'sosial', dan pragmatik 'makna secara eksternal'. Keberadaan sosiopragmatik berawal dari eksistensi ilmu pragmatik. Pragmatik berkembang dengan pesat karena mampu menjawab masalah kebahasaan yang tidak tuntas terjawab oleh teori-teori linguistik sebelumnya. Permasalahan yang dimaksudkan adalah fenomena kebahasaan yang berkaitan dengan sosial budaya. Pragmatik adalah sebagai studi bahasa yang mempelajari relasi bahasa dengan konteksnya (Levinson, dalam jurnal Mohd. Fauzi dkk, 2017). Pragmatik adalah cabang ilmu bahasa yang mempelajari struktur bahasa secara eksternal, yakni bagaimana satuan kebahasaan itu digunakan di dalam komunikasi. Ketika bentukbentuk dan penggunaan kebahasaan dikaji dengan menghubungkannya pada kondisikondisi setempat atau khusus, maka hal ini berada dalam kawasan 
sosiopragmatik (Revita, dalam jurnal Mohd. Fauzi dkk, 2017). Revita selanjutnya mengatakan bahwa Sosiopragmatik merupakan cabang ilmu linguistik yang mengkaji bahasa dengan pendekatan sosial dan pragmatik.

Paker mengungkapkan dalam jurnal (Rosida Tiurma M, 2010) Kajian sosiopragmatik merupakan kajian pragmatik yang menggunakan pendekatan sosial. Kajian sosiopragmatik menganalisis aspek-aspek makna suatu peristiwa tindak tutur yang ditinjau dari konteks situasi pertuturan dan konteks sosial budaya di mana bahasa itu digunakan Sosiopragmatik mempelajari ilmu yang mengkaji bentuk tuturan untuk memahami maksud penutur sesuai dengan konteks sosialnya, misalnya, konteks jenis kelamin, profesi, latar budaya, suku, adat-istiadat, perilaku atau gaya hidup.

\section{Pengertian Kesantunan Berbahasa}

Kesantunan berbahasa tercermin dalam tatacara berkomunikasi lewat tanda verbal atau tatacara berbahasa. Ketika berkomunikasi, kita tunduk pada norma-norma budaya, tidak hanya sekedar menyampaikan ide yang kita pikirkan. Tatacara berbahasa harus sesuai dengan unsur-unsur budaya yang ada dalam masyarakat tempat hidup dan dipergunakannya suatu bahasa dalam berkomunikasi. Apabila tatacara berbahasa seseorang tidak sesuai dengan norma-norma budaya, maka ia akan mendapatkan nilai negatif, misalnya dituduh sebagai orang yang sombong, angkuh, tak acuh, egois, tidak beradat, bahkan tidak berbudaya.

Kesantunan bersifat relatif di dalam masyarakat. Ujaran tertentu biasa dikatakan santun di dalam suatu kelompok masyarakat tertentu, akan tetapi di kelompok masyarakat lain bisa dikatakan tidak santun. Tujuan kesantunan termasuk kesantunan berbahasa adalah membuat suasana berinteraksi menyenangkan, tidak mengancam muka dan efektif. Markhamah (dalam skripsi Rosita Wulandari, 2016: 24) menyatakan bahwa kesantunan merupakan suatu cara yang dilakukan penutur saat berkomunikasi supaya penutur tidak merasa tertekan, tersudut, dan tersinggung. Kesantunan berbahasa dalam hal ini berupaya untuk menjaga harga diri pembicara maupun pendengar. Penggunaan bahasa yang santun saat berkomunikasi akan membuat mitra tutur dan lawan bicara merasa dihormati, nyaman, dan tidak menimbulkan kesalahpahaman. Dapat disimpulkan bahwa kesantunan berbahasa merupakan bagian dari etika dalam hubungan komunikasi agar tercipta dengan baik, santun dan mencegah adanya permasalahan dalam segala kegiatan yang dilakukan manusia. Wijana (2018) menyatakan bahwa Leech membagi prinsip kesantunan 
menjadi enam yang terdiri dari; maksim kebijaksanaan, maksim penerimaan, maksim kemurahan, maksim kerendahan hati, maksim kecocokan, serta maksim kesimpatian.

Sebelum membicarakan lebih jauh keenam maksim kesantunan di atas ada baiknya terlebih dahulu diterangkan mengenai bentuk-bentuk ujaran yang digunakan untuk mengekspresikan maksim-maksim di atas. Bentuk-bentuk ujaran yang dimaksud adalah bentuk ujaran imposif, komisif, ekspresif, dan asertif. Bentuk ujaran komisif adalah bentuk ujaran yang berfungsi untuk menyatakan janji atau penawaran. Ujaran imposif adalah ujaran yang digunakan untuk menyatakan perintah atau suruhan. Ujaran ekspresif adalah ujaran yang digunakan untuk menyatakan sikap psikologis pembicara terhadap sesuatu keaadaan. Ujaran asertif adalah ujaran yang lazim digunakan untuk menyatakan kebenaran proposisi yang diungkapkan.

\section{Prinsip Kesantunan Berbahasa}

Prinsip kesantunan berbahasa menurut Leech (Wijana, 2018) terdiri atas enam maksim, yakni maksim kebijaksanaan, maksim penerimaan, maksim kemurahan, maksim kerendahan hati, maksim kecocokan, dan maksim kesimpatian.

1. Maksim Kebijaksanaan

Maksim ini menurut Leech dalam (Wijana, 2018) mengharuskan setiap penutur untuk meminimalkan kerugian orang lain, atau memaksimalkan keuntungan bagi orang lain. Maksim ini diungkapkan dengan kalimat imposif dan kalimat komisif.

2. Maksim penerimaan

Dalam (Wijana, 2018) Leech mengungkapkan bahwasanya prinsip maksim penerimaan adalah penutur untuk memaksimalkan kerugian bagi diri sendiri dan meminimalkan keuntungan bagi diri sendiri. Maksim ini diungkapkan dengan kalimat imposif dan kalimat komisif.

3. Maksim Kemurahan

Berbeda dengan maksim kebijaksanaan dan maksim penerimaan, maksim kemurahan diungkapkan dengan kalimat ekspresif dan kalimat asertif. Dengan penggunaan kalimat ekspresif dan asertif ini menjadi jelas bahwa tidak hanya dalam menyuruh atau menawarkan sesuatu saja seseorang harus berlaku santun, tetapi dalam mengungkapkan perasaan dan menyatakan pendapat ia tetap diwajibkan berperilaku demikian. Leech (Wijana, 2018) 
mengungkapkan maksim kemurahan ini menuntut setiap penutur untuk memaksimalkan rasa hormat kepada orang lain dan meminimalkan rasa tidak hormat kepada orang lain.

4. Maksim Kerendahan Hati

Maksim kerendahan hati juga diungkapkan dengan kalimat ekspresif dan asertif. Jika maksim kemurahan berpusat pada orang lain, maksim kerendahan hati menuntut setiap penutur untuk memaksimalkan ketidakhormatan pada diri sendiri dan meminimalkan rasa hormat pada diri sendiri.

5. Maksim Kecocokan

Leech (Wijana, 2018) menjelaskan bahwa maksim kecocokan mengharuskan setiap penutur dan lawan tutur untuk memaksimalkan kecocokan di antara mereka dan meminimalkan ketidakcocokan di antara mereka. Maksim ini diungkapkan dengan kalimat ekspresif dan kalimat asertif.

6. Maksim Kesimpatian

Maksim kesimpatian ini mengharuskan setiap penutur memaksimalkan rasa simpati dan meminimalkan rasa antipati kepada lawan tuturnya. Leech (Wijana, 2018) menambahkan Jika lawan tutur mendapatkan kesuksesan atau kebahagiaan, penutur wajib memberikan ucapan selamat. Jika lawan tutur mendapatkan kesusahan ataupun musibah penutur layak turut berduka cita atau mengutarakan ucapan belasungkawa. Maksim ini diungkapkan dengan kaliamt ekspresif dan kalimat asertif.

\section{Pelanggaran Prinsip Kesantunan}

Chaer mengungkapkan dalam tesis (Nanang Kusworo 2019: 122) bahwa ada beberapa faktor atau hal yang menyebabkan sebuah pertuturan itu menjadi tidak santun. Penyebab ketidaksantunan antara lain,

1. Kritik secara langsung dengan kata-kata kasar

Kritik kepada mitra tutur secara langsung menyebabkan sebuah pertuturan menjadi tidak santun. Apalagi kritikan itu diungkapkan dengan kata-kata kasar yangdapat menyinggung perasaan mitra tutur atau lawan tutur.

2. Dorongan rasa emosi penutur 
Tuturan yang kadang kala diungkapkan oleh penutur dengan rasa emosi dianggap tidak santun karena memberikan kesan amarah kepada mitra tutur atau lawan tutur.

3. Protektif terhadap pendapat

Tuturan penutur yang protektif terhadap pendapatnya dianggap tidak santun karena seolah-olah memperlihatkan pada orang lain atau mitra tutur bahwa pendapatnya benar dan pendapat orang lain.

4. Sengaja menuduh lawan tutur

Sengaja menuduh lawan tutur merupak tindakan yang tidak santun karena penutur seolah-seolah menunjukan rasa kecurigaannya kepada lawan tutur.

5. Sengaja memojokkan mitra tutur

Tuturan penutur yang sengaja diungkapkan untuk memojokkan mitra tutur dianggap tidak santun karena membuat mitra tutur atau lawan tutur tidak berdaya melawan untuk melakukan pembelaan.

\section{B. Metode Penelitian}

Penelitian ini merupakan penelitian deskriptif kualitatif. Menurut Sugiyono (2015: 13) bahwa metode deskriptif kualitatif adalah penelitian yang dilaksanakan untuk mengetahui masalah itu sendiri tanpa membandingkan atau menghubungkan antara masalah yang ada dengan gambaran tanpa interversi dari peneliti terhadap suatu fenomena. Berdasarkan hal tersebut, dapat dikatakan bahwa pendekatan penelitian ini merupakan pendekatan kualitatif. Hal tersebut disebabkan data yang dikumpulkan berupa tuturan dewan juri ragam acara "BerAKSI di Rumah Saja" di Indosiar. Penelitian ini berjenis deskriptif karena bertujuan memberikan gambaran tentang pemenuhan prinsip kesantunan berbahasa dan pelanggaran prinsip kesantunan berbahasa dalam ragam acara "BerAKSI di Rumah Saja di Indosiar".

Sumber data penelitian ini adalah video ragam acara BerAKSI di Rumah Saja di Indosiar yang diperoleh dari tayangan di Youtube yang diakses melalui (https://www.youtube.com/channel/UCYqOeAXJm8yV9sJ8Ud3cR7A) dari bulan April sampai bulan Mei. Data penelitian ini adalah tuturan dewan juri ragam acara "BerAKSI di Rumah Saja" yang mengandung pemenuhan prinsip kesantunan berbahasa dan pelanggaran prinsip kesantunan berbahasa. 
Metode pengumpulan data yang digunakan dalam penelitian ini adalah dokumentasi serta teknik simak dan teknik catat. Teknik dokumentasi digunakan karena data yang diambil sudah tersedia dan dapat dilihat melalui tayangan di Youtube. Teknik catat dilakukan untuk mencatat data berupa tuturan yang memenuhi dan melanggar maksim kesantunan yang diperoleh ketika menyimak tayangan "BerAKSI di Rumah Saja" di Indosiar. Pengumpulan data berupa video tayangan "BerAKSI di Rumah Saja" yang di unduh melalui Youtube mulai bulan April 2020 - bulan Mei 2020.

\section{Pembahasan}

\section{Maksim Kebijaksanaan}

\section{DT4.1}

Abdel: Mpok lemeh kan udah di salamin

Ramzi: Ya, tapi lu gak bisa ngelarang dia ngucapin salam juga del.

Abdel: Iya sih, tapi kan udah diwakilin

Ustaz Taufiqurraman: Cing Abdel itu mpok Lemeh mau bantuin cing Abdel....

KONTEKS: Dalam segmen ini Abdel membawakan berita AKSI. Saat membaca berita patung mpok Lemeh menyahut mengucapkan salam sehingga membuat Abdel kesal.

Pada data (4.1) ustaz Taufiqurrahman mengingatkan Abdel untuk tidak bertingkah kesal terhadap mpok Lemeh. Karena, menurut ustaz Taufiqurrahman mpok Lemeh hanya ingin membantu Abdel agar acaranya lebih bagus. Sehingga, hal ini bisa dijadikan dasar bahwa tuturan ustaz Taufiqurrahman menunjukkan adanya pemenuhan maksim kebijasanaan. Leech dalam (Wijana, 2018: 54) mengatakan bahwa maksim kebijaksanaan dilaksanakan dengan cara memaksimalkan keuntungan bagi orang lain atau meminimalkan kerugian bagi orang lain. Hal ini terlihat dari tuturan ustaz Taufiqurrahman yang memaksimalkan keuntungan bagi Abdel agar berperilaku lebih baik dan meminimalkan kerugiannya karena akan dipandang tidak sopan oleh orang lain akibat rasa kesalnya kepada mpok Lemeh.

\section{Maksim Kemurahan}

\section{DT4.2}

Ustaz Taufiqurrahman: Jadi ini buat abah ya ,,, ini tawadhu'nya seorang guru ya...Dari keramat langsung ke pasar baru, Bekel pasar dan markisa, Kami ucapkan selamat buat ayahanda guru ya memang dia pahlawan tanpa tanda jasa.

KONTEKS: $\quad$ Ustaz Ulin menghadirkan ayahnya ketika tampil di berAKSI di Rumah Saja. Dalam pembicraaanya ustaz Ulin mengatakan kalau ayahnya adalah sosok yang selama ini selalu menemani, membimbing dan bahkan menyiapkan kostum untuk ustaz Ulin saat akan tampil di AKSI di Indosiar. Melihat ketelatenan ayah ustaz 
Ulin, ustaz Taufiqurrahman tersanjung dan memberikan hormat kepada ayah ustaz Ulin.

Dalam tuturan data (4.2) berupa tindak tutur lokusi yang bertujuan untuk memberikan informasi mengenai rasa hormat ustaz Taufiqurrahman kepada ayah ustaz Ulin. Dalam tuturannya terlihat sangat jelas ustaz Taufiqurrahman telah memenuhi prinsip kesantunan berbahasa berupa maksim kemurahan. Dalam pantunnya ustaz Taufiqurrahman menyebutkan ayah ustaz Ulin adalah seorang guru tanpa tanda jasa. Selain itu, tuturan yang di ungkapkan ustaz Taufiqurrahaman juga cukup lumayan panjang karena diungkapkan dalam bentuk pantun. Semakin panjang tuturan maka semakin menunjukkan kalau penutur menghormati lawan tuturnya. Sehingga, dapat disimpulkan ustaz Taufiqurrahman sangat memaksimalkan rasa hormatnya kepada ayah ustaz Ulin.

\section{Maksim Kerendahan hati}

DT4.13

Ustaz Taufiqurrahman: Ustaz Dani, ini mewakili semuanya... ke bekasi bareng nyonya, makan lesehan sampek ke mekah, makasih kirimanya semoga makin berkah. KONTEKS: Salah satu peserta AKSI yaitu ustaz Dani mengirimkan parfum untuk diberikan kepada para pembawa acara dan dewan juri "BerAKSI di Rumah Saja”.

Data (4.13) menunjukkan pemenuhan prinsip kesantunan berbahasa berupa maksim kerendahan hati yang berarti meminimalkan rasa hormat pada diri sendiri. Wijana (2018) mengungkapkan kalau maksim kerendahan hati ini berpusat pada diri sendiri. Berbeda dengan maksim kemurahan yang berpusat pada orang lain. Tuturan ustaz Subki pada data (4.13) memperlihatkan bahwa ustaz Subki meminimalkan rasa hormat pada dirinya sendiri dengan cara berterimakasih kepada ustaz Dani atas pemberian yang telah diberikan. Selain itu, pemenuhan pada maksim kerendahan hati ditunjukan ustaz Subki pada saat meminimalkan rasa hormat pada dirinya sendiri dengan cara mewakili para pembawa acara dan dewan juri lainnya untuk mengucapkan terima kasih kepada ustaz Dani.

\section{Maksim Kecocokan}

DT4.7

Ramzi: Tapi kita penasaran betul apa yang sudah disampaikan

Ustaz Solmed: Oh, oke, baik karena yang tanya abi ramzi pasti saya jawablah, CS KONTEKS: Segmen ini menampilkan ustaz Maruli salah satu peserta AKSI yang saling berbicara menggunakan bahasa dari daerah Sumatra Utara yang tidak dimengerti oleh para pembawa acara. 
Dalam data (4.7) menunjukkan adanya pemenuhan prinsip kesantunan berupa maksim kecocokan. Pertama, hal ini ditunjukan dengan tuturan ustaz Solmed yang mengatakan kalau Ramzi dan ustaz Solmed adalah "CS" atau teman dekat. Kedua, maksim kecocokan ini terlihat saat ustaz ditanya oleh Abdel tentang pertanyaan yang sama. Saat Abdel bertanya ustaz Solmed tidak langsung menjawab. Tetapi, ketika Ramzi yang bertanya ustaz Solmed terlihat begitu baik dan mengatakan kalau Ramzi yang bertanya dia akan menjawab. Melihat dari tuturan sekaligus ekspresi dari ustaz Solmed dalam tuturan data (4.7) terlihat adanya kecocokan antara Ramzi dan ustaz Solmed. Sehingga dengan adanya kecocokan diantara penutur dan lawan tutur membuat proses komunikasi menjadi lebih baik karena adanya rasa saling menghargai satu sama lain.

\section{Maksim Kesimpatian}

DT4.30

Ustaz Subki: $\quad$ Setiap yang berjiwa pasti akan menjumpai kematian dan kematian bagai sebuah pintu dan setiap kita akan memasuki pintu. Dan kematian adalah merupakan nasihat bagi kita semua yang masih hidup kalau yang berpulang membawa ratusan karya mudah-mudahan kita juga sebelum kembali menyempatkan diri beramal sholeh untuk menghadap Allah SWT. Seperti yang disampaikan tadi, hari ini sebagaimana nabi mengatakan kalau ada saudara kita yang dikubur doakan, mohonkan ampun untuknya.

KONTEKS: Ramzi mempersilahkan kepada ustaz Subki untuk memimpin doa yang ditujukan kepada almarhum Didi Kempot.

Dalam data (4.30) terlihat sekali bahwa tuturan ustaz Subki menunjukkan rasa berbela sungkawa atas kepergian almarhum Didi Kempot. Lewat doa yang panjang beliau ungkapkan untuk menunjukkan rasa simpatinya terhadap kepergian sang legendaris musik keroncong itu. seperti yang kita ketahui seseorang dikatakan santun dalam masyarakat adalah ketika dia menunjukkan rasa simpati terhadap sesamanya. Rasa simpati tidak hanya ditunjukkan ketika seseorang mendapatkan kesusahan saja melainkan bisa ditunjukkan ketika seseorang mendapat kebahagiaan.

\section{Pelanggaran Prinsip Kesantunan Berbahasa}

\section{Kritikan Secara Langsung}

DT4.10

\section{Subki: Eh, Abdel...lu nyari koran emang orangnya tabrak kereta}

KONTEKS: Kedatangan penyanyi jebolan LIDA, Hari membuat Lesti terkagumkagum dan salah tingkah. Tingkah salah tingkah Lesti yang berakting pingsan saat terpesona dengan Hari. Embuat Abdel mencari-cari koran seolah-olah ingin menutupi jenazah seseorang. 
Tuturan ustaz Subki dalam data (4.10) di atas memperlihatkan kalau ustaz Subki melanggar prinsip kesantunan berbahasa pada makism kemurahan. Dalam maksim kemurahan penutur harus menunjukkan rasa hormatnya terhadap orang lain atau lawan tutur. Namun, yang terlihat dari tuturan ustaz Subki di atas memperlihatkan kebalikannya. Ustaz Subki mengkritik Abdel yang yang berakting mencari koran untuk menutupi Lesti yang berakting pingsan. Kritikan atau tuturan ustaz Subki terlihat begitu kasar karena menuduh Abdel seolah-olah ingin menutupi jenazah seseorang yang ditabrak kereta.

\title{
2. Dorongan Rasa Emosi Penutur
}

DT4.6

\begin{abstract}
Abdel: Jadi tadi itu bahas apa?
Ustaz Solmed: Mau tahu aje lu!

KONTEKS: $\quad$ Dialog di atas terjadi saat ustaz. Solmed akan memberikan komentar untuk peserta AKSI yaitu ustaz Maruli. Namun sebelum berkomentar ustaz Solmed menyapa ustaz Maruli menggunakan bahasa daerah Sumatra Utara yang tidak dimengerti oleh para pembawa acara.
\end{abstract}

Dalam data (4.6) seharusnya penutur memaksimalkan keuntungan orang lain. Tetapi, dalam tuturan data (4.6) ustaz Solmed justru memaksimalkan kerugian bagi Abdel karena tidak mau menjawab pertanyaan Abdel. Pelanggaran terhadap prinsip kesantunan ini disebabkan adanya dorongan emosi ustaz Solmed terhadap Abdel. Dorongan emosi ustaz Solmed terhadap Abdel bisa dibandingkan dengan tuturan beliau kepada Ramzi dalam data (4.8). pada tuturan data (4.8) menunjukkan adanya pemenuhan prinsip kesantunan dalam maksim kecocokan yang terlihat dari tuturan ustaz Solmed yang mau menjawab pertanyaan dari Ramzi karena ada kedekatan antara mereka berdua. Dari sini, dapat dibenarkan bahwa tuturan (4.6) melanggar prinsip kesantunan karena adanya dorongan emosi.

\section{Sengaja menuduh lawan tutur}

\section{DT4.36}

Abdel: Dapet salam dari temen pesantren waktu itu, cewek, depannya $R$ Ustaz Solmed: cewek....?

Abdel: He eh

Ustaz Solmed: Jangan bercanda...

KONTEKS: Abdel menyampaikan salam dari teman perempuan ustaz Solmed sewaktu di pesantren. Tepai, ustaz Solmed tidak mempercayainya.

Dalam data (4.36) memperlihatkan adanya pelanggaran prinsip kesantunan pada maksim kebijakasanaan karena memaksimalkan kerugian mitra tutur. Padahal Leech (Wijana, 2018) mengungkapkan maksim kebijaksanaan berprinsip penutur memaksimalkan keuntungan bagi orang lain dan meminimalkan kerugian bagi orang 
lain. Tuturan ustaz Solmed terlihat menuduh atau menganggap Abdel bohong mengenai teman perempuan yang dikatakan Abdel. Tindakan ustaz Solmed ini dikatakan tidak santun karena menuduh mitra tutur dan menimbulkan kecurigaan bagi penutur bahwa mitra tutur berbohong. Anggapan atau tuduhan penutur tentu merugikan mitra tutur karena mitra tutur dianggap berbohong padahal kenyataanya belum tentu mitra tutur berbohong.

\section{Sengaja memojokkan mitra tutur}

\section{DT4.20\&DT4.21}

Ustaz Taufiqurrahman: Abi Ramzi, cing Abdel, ni ustaz Solmed berani nanggapi karena menganggap april udah kelar (hahaha)

Ustaz Subki: Jangankan ustad Solmed begitu tadi ustazah April nyaut teh saya ampe butek

Abdel: Ya emang butek, kalau bening air putih

KONTEKS: $\quad$ Ustaz Solmed ditegur suara istrinya karena ketahuan menggona

Uyaina. Suara istri ustaz Solmed membuat ustaz Solmed terpojok.

Dalam data (4.20) dan data (4.21) menunjukkan pelanggaran prinsip kesantunan dikarenakan ustaz Taufiqurrahman dan ustaz Subki sengaja memojokkan ustaz Solmed karen aketahuan menanggapai Uyaina. Memojokkan mitra tutur dianggap tidak santun dalam berbahasa karena menurut Chaer (dalam tesis Nanang Kusworo, 2019) membuat mitra tutur tidak berdaya dan merasa rendah. Begitupun dalam tuturan data (4.20) dan data (4.21) terlihat sanagat memojokkan ustaz Solmed sampai ustaz Solmed tidak berani berkomentar lagi.

\section{Simpulan}

Berdasarkan temuan penelitian Data yang ditemukan dalam penelitian ini sebanyak 52 tuturan dan pembahasan yang dilakukan, dapat disimpulkan ada tiga hal yang merupakan jawaban dari rumusan masalah. Ketiga simpulan tersebut adalah sebagai berikut.

Pemenuhan pada prinsip kesantunan berbahasa ditunjukan pada lima maksim saja yaitu, maksim kebijasanaan ditemukan 8 tuturan, maksim kemurahan ditemukan 6 tuturan, maksim kerendahan hati ditemukan 1 tuturan, maksim kecocokan ditemukan 1 tuturan, dan maksim kesimpatian ditemukan 1 tuturan. Sedangkan maksim penerimaan tidak ditemukan hasilnya dalam penelitian ini.

Pelanggaran terhadap prinsip kesantunan ditemukan terhadap maksim kebijaksanaan, maksim kemurahan, maksim kerendahan hati dan maksim penerimaan sedangkan untuk pelanggaran terhadap maksim kecocokan dan maksim kesimpatian tidak ditemukan hasinya dalam penelitian ini. 
Faktor-faktor yang memengaruhi pelanggaran prinsip kesantunan dalam penelitian ini yaitu; kritikan secara langsung dengan kata-kata kasar ditemukan 16 tuturan, dorongan rasa emosi ditemukan 5 tuturan, sengaja menuduh lawan ditemukan 8 tuturan, dan sengaja memojokkan mitra tutur ditemukan 8 tuturan. Sedangkan, faktor lainnya seperti protektif terhadap pendapat tidak ditemukan hasinya dalam penelitian ini.

\section{Daftar Rujukan}

Anggun Purwati, Ni Made. Rasna, Wayan. Rai Wisudariani, Ni Made. 2017. Prinsip Kesantunan Pada Takshow Rumpi (No Secret) Di Trans TV. Singaraja: Universitas Pendidikan Ganesha. Diakses dari (https://ejournal.undiksha.ac.id/index.php/JJJPBS/article/view/9538) pada 4 Juni 2020.

Chaer, Abdul. 2018. Linguistik umum. Jakarta: Rineka Cipta.

Chaer, Abdul. Agustina, Leonie. 2014. Sosiolinguistik. Jakarta: Rineka Cipta.

Fauzi, Mohd, dkk, Analisis Litotes Dalam Drama Macbeth Karya William Shakespeare: Kajian Sosiopragmatik. Diakses dari (https://scholar.google.co.id/scholar?hl=id\&as_sdt=mohd+fauzi) pada 29 Juli 2020.

Gischa, Seraficha. Pengertian bahasa, fungsi dan manfaatnya, diakses dari https://www.kompas.com/skola/read/2020/01/29/060000069/,pada 21 Mei 2020.

Kusumastuti, Ayuningtyas. 2010. Kesantunan Berbahasa Indonesia Pembawa Acara Stasiun Televisi Swasta Nasional. Skripsi Tidak Diterbitkan. Yogyakarta: Universitas Sanata Dharma diakses dari (https://repository.usd.ac.id/21347/2/051224019_Full.pdf). Pada 08 Juni 2020.

Kusworo, Nanang. 2019. Pelanggaran Kesantunan Tuturan Pendidik Dan Peserta Didik Dalam Interaksi Pembelajaran Di Sekolah Menengah Pertama Islam Terpadu Bina Insani. Tesis Tidak Diterbitkan.Universitas Negeri Semarang. Diakses dari (https://lib.unnes.ac.id/35142/) pada 08 Juni 2020.

Leech, Geoffrey. 2011. Prinsip-Prinsip Pragmatik. Jakarta: Universitas Indonesia.

Natashia, Liony. Apa itu kesantunan berbahasa dan apa saja prinsip-prinsip kesantunan berbahasa, diakses dari https://www.kompasiana.com/lionynatashia/56947eafbd34058345d4, pada 21 Mei 2020.

Nazir. Moh, 2003, Metode Penelitian.Jakarta: PT. Ghalia Indonesia.

Nurjamily, Wa Ode. 2015. Kesantunan Berbahasa Indonesia dalam Lingkungan Keluarga. Diakses dari (http://ojs.uho.ac.id/index.php/HUMANIKA/article/view/608) pada 04 Juni 2020. 
Sulistyo Sari, Ellysya. 2019. Pelanggaran Prinsip Kesantunan Berbahasa dalam Acara Dua Arah Kompas TV. Surabaya: Universitas Negeri Surabaya. Diakses dari (https://jurnalmahasiswa.unesa.ac.id/index.php/jurnalsapala/article/view/22840). Pada 08 Juni 2020.

Wahyuni, Wida. 2018. Analisis Maksim Kesantunan Berbahasa Indonesia Dakwah Ustaz Nur Maulana Melalui Trans TV. Universitas Negeri Semarang. Diakses dari (https://core.ac.uk/download/pdf/159383463.pdf). Pada 04 Juni 2020.

Wijana, I Dewa Putu. Rohmadi Muhammad. 2018. Analisis Wacana Pragmatik. Surakata : Yusma Pustaka.

Wulandari, Rosita. 2016. Kesantunan berbahasa pada acara Mata Najwa di Metro TV. Skripsi Tidak Diterbitkan. Universitas Negeri Semarang. Diakses dari (https://lib.unnes.ac.id/29308/) pada 04 Juni 2020.

Moh. Syamsul Ma'arif, S. Q. R. (2021). Kajian Fonologi Bahasa Indonesia dalam Kumpulan Video Mak Beti Karya Arif Muhammad. PENEROKA, 1(01), 151-170.

Ridwan, M. H. (2017). Peningkatan Keterampilan Menyimak Berita Dengan Media Audio Visual Siswa Smp Plus Darussalam Blokagung Banyuwangi. JURNAL DARUSSALAM, JURNAL PENDIDIKAN, KOMUNIKASI, DAN PEMIKIRAN HUKUM ISLAM, IX(1), $32-49$. 